\title{
Chromosome Number and Karyotype Variation in Codiaeum variegatum Cultivars
}

\author{
Min Deng ${ }^{1}$, Jianjun Chen ${ }^{2}$, Richard J. Henny, and Qiansheng $\mathbf{L i}^{1}$ \\ University of Florida, Institute of Food and Agricultural Sciences, \\ Department of Environmental Horticulture and Mid-Florida Research and \\ Education Center, 2725 Binion Road, Apopka, FL 32703-8504
}

Additional index words. croton, polyploidy, tropical ornamental foliage plants

\begin{abstract}
Codiaeum variegatum (L.) Blume is one of the most popular ornamental foliage plants. It encompasses more than 300 recognized cultivars valued by their wide range of leaf shapes and vivid foliage colors. Thus far, only limited information is available regarding the genetic basis of their leaf morphological variation. This study investigated the chromosome numbers and karyotypes of seven phenotypically diverse cultivars. Root-tip cells were fixed, mounted, and observed under light microscopy. Results showed that chromosome numbers in the mitotic metaphase of the seven cultivars were high and variable and ranged from $2 n=66,70,72,76,80,82,84$, to $2 n=96$, indicating that the cultivars are polyploid and some could be aneuploid. Genetic mosaics occurred in one of the seven cultivars. Additionally, each cultivar had its own karyotype. There were no relationships between chromosome numbers or karyotypes and leaf morphology. Results from this study suggest that the morphological diversity among cultivars of this species could be in part attributed to high variation in chromosome numbers and karyotypes.
\end{abstract}

Codiaeum variegatum (L.) Blume, commonly known as crotons, are small evergreen trees and shrubs that are popular as ornamental plants because of their attractive foliage. Currently, more than 300 croton cultivars are reported in the world (Brown, 1995), and they are produced as either landscape plants or containerized foliage plants (Chen et al., 2005). The foliage varies widely in leaf size, shape, color, and variegation pattern among the cultivars. Leaf sizes range from small $(6$ $\mathrm{cm}$ long $\times 1 \mathrm{~cm}$ wide) to large $(35 \mathrm{~cm}$ long $\times$ $13 \mathrm{~cm}$ wide), and margins can be entire or trifurcate. Leaf shapes differ from simple ovate to linear to spiral; some are slightly or deeply cut, connected along the blade only by the midrib. Because they are prized by the leaf morphology, The Croton Society (2009) categorized croton cultivars into nine types based on their leaf shapes: 1) broad leaf; 2) oak leaf; 3) semioak-leaf; 4) spiral leaf; 5) narrow leaf; 6) very narrow leaf; 7) small leaf; 8) interrupted leaf; and 9) recurved leaf.

Native to the Mollucan Islands of Indonesia (Brown, 1995), crotons were first introduced to England in 1804, and hybrids were developed in Belgium and France during the

Received for publication 19 Jan. 2010. Accepted for publication 22 Feb. 2010.

We thank Green Terra, Inc., Coral Springs, FL, and Hermann Engelmann Greenhouses, Inc., Apopka, $\mathrm{FL}$, for providing plant materials used in this study and Russell D. Caldwell for assistance in plant collection and for critical review of the manuscript. ${ }^{1}$ Current address: School of Ecological Technology and Engineering, Shanghai Institute of Technology, Shanghai, China.

${ }^{2}$ To whom reprint requests should be addressed; e-mail jjchen@ufl.edu.
1800 s. The hybrids were introduced into the United States in 1871 and subsequently were further hybridized in south Florida during the 1920 s and 1930s, which resulted in the release of more than 70 hybrid cultivars, commonly known as Florida hybrids (Brown, 1995). Crotons are monoecious with poor seed set. Seed propagation often results in plants with different phenotypes (Sharma and Bal, 1958). Thus, once a hybrid cultivar is selected, it is propagated through stem cuttings (Chen and Stamps, 2006).

Although crotons have a long history of introduction and hybridization, there is limited information regarding the genetic basis of their morphological variation. Sharma and Bal (1958) examined chromosome numbers in root-tip cells of 24 croton varieties collected from India and found that all the varieties studied were polyploid. Subsequent research by Pancho and Hilario (1963) from the Philippines and Chennaveeraiah and Wagley (1985) from India also suggested that the croton cultivars they studied were polyploid. Recently, Ogunwenmo et al. (2007) studied root-tip cells of six crotons cultivated in Nigeria and reported that four of the six cultivars had $2 n=60$, but one had $2 n=24$ and the other $2 n=30$.

Florida has a rich history in croton cultivar development and also leads the nation in croton production (Brown, 1995). However, there is no information regarding the cytology of crotons cultivated in Florida. The objectives of this study were to examine the chromosome number and karyotype of selected crotons cultivated in Florida and to determine if any relationships exit between chromosome numbers or karyotype and leaf morphology.
Plant materials. Seven croton cultivars (Curly Boy, Gold Dust, Ice Tone, Mother and Daughter, Ralph Davis Hybrid, Yellow Petra, and Picasso's Paint Bush; Fig. 1) were gathered from germplasm maintained at the University of Florida's Mid-Florida Research and Education Center and from ornamental foliage plant nurseries in central and southern Florida. The seven cultivars represent five leaf types: spiral ('Curly Boy'), small ('Gold Dust' and 'Ice Tone'), interrupted ('Mother and Daughter), broad ('Ralph Davis Hybrid' and 'Yellow Petra'), and very narrow leaf ('Picasso's Paint Bush') and are also among the most popular ones cultivated in Florida.

Stem cuttings were rooted in $20-\mathrm{cm}$ diameter plastic pots using a sphagnum peatbased medium (Canadian peat: vermiculite: perlite at a 3:1:1 ratio based on volume), five pots per cultivar. After rooting, plants were grown in a shaded greenhouse under daily maximum photosynthetically photon flux $(P P F)$ density of $350 \mu \mathrm{mol} \cdot \mathrm{m}^{-2} \cdot \mathrm{s}^{-1}$ at a temperature range of 20 to $32{ }^{\circ} \mathrm{C}$. All plants were fertilized with a top-dress application of $8 \mathrm{~g}$ Multicote $\left(15 \mathrm{~N}-7 \mathrm{P}_{2} \mathrm{O}_{5}-15 \mathrm{~K}_{2} \mathrm{O}\right)$ controlledrelease fertilizer with an 8-month longevity (Haifa Chemicals Ltd., Haifa Bay, Israel) and hand-watered two to three times a week as needed. Six months after growing in the shaded greenhouse, the cultivars were used for the following cytological studies.

Chromosome number determination. Ten root tips, two per pot, were collected from each cultivar in the morning and pretreated as described by Dyer (1979) with modifications. Briefly, root tips were treated with $2.0 \mathrm{~mm} 8$ hydroxyquinoline solution for $3 \mathrm{~h}$ at room temperature. The root tips were then fixed in a 1:3 acetic acid:absolute ethanol solution overnight at $4{ }^{\circ} \mathrm{C}$ and preserved in a $70 \%$ ethanol solution at $-20{ }^{\circ} \mathrm{C}$. Fixed root tips were softened by hydrolyzation in $1 \mathrm{M} \mathrm{HCl}$ solution at $60{ }^{\circ} \mathrm{C}$ for $5 \mathrm{~min}$, rinsed briefly in distilled water, and stained with $2 \%$ acetoorcein for $15 \mathrm{~min}$. The root tips were mounted on a glass slide with a fresh drop of the stain and covered with a coverslip. The glass slide was warmed by alcohol flame for a few seconds. The coverslip was tapped gently with fine forceps and squashed using the thumb. Chromosome numbers were determined by counting at least 10 complete well-spread mitotic metaphase cells, one cell per root tip, using a Nikon Optiphot Pol microscope (Nikon Nippon Kogaku K.K., Tokyo, Japan). Images were taken by a Canon S3 IS digital camera (Cannon U.S.A., Inc., Lake Success, NY).

Karyotype determination. Karyotypes were analyzed in reference to the method of Sharma and Bal (1958). At least four complete well-spread mitotic metaphase cells of each cultivar were photographed and the lengths of chromosome arms were measured. Chromosomes were classified into two types: A) chromosomes without secondary constrictions; and B) chromosomes with one to three secondary constrictions. According to the position of the primary constriction (centromere), 
type A chromosomes were divided into two subtypes: $A_{1}$ ) metacentric to submetacentric chromosome (Stebbins, 1971) with centromere located at the middle or submiddle of the chromosome; and $\mathrm{A}_{2}$ ) acrocentric chromosome with centromere close to the terminal area. Type B chromosomes were divided into four subtypes based on the secondary constriction positions: $\mathrm{B}_{1}$ ) metacentric to submetacentric chromosome with a secondary constriction on the longer arm that divided it into equal parts; $B_{2}$ ) metacentric to submetacentric chromosome with a secondary constriction on the longer arm that divided it into unequal parts; $\mathrm{B}_{3}$ ) acrocentric chromosome with a secondary constriction close to the end of the longer arm that divided it into unequal parts; and $\mathrm{B}_{4}$ ) chromosome with more than one secondary constriction. The final karyotype of each cultivar and/or the different karyotypes within a cultivar were the result of separate examinations of four well-spread mitotic metaphase cells.

\section{Results}

Chromosome number variation. Somatic chromosome numbers were high and variable ranging from $2 n=66$ to 96 (Table 1), which suggest that the seven cultivars are polyploid. There were no relationships between chromosome number and leaf morphology. For example, 'Curly Boy' and 'Yellow Petra' each had a $2 n$ chromosome number of 72 . 'Curly Boy' has narrow, spiral leaves (Fig. 1A), whereas 'Yellow Petra' has broad leaves (Fig. 1F). Both 'Gold Dust' and 'Ice Tone' have elliptic, small leaves, but 'Gold Dust' had $2 n=80$ and 'Ice Tone' $2 n=76$. Also, both 'Ralph Davis Hybrid' and 'Yellow Petra' have broad leaves, but the former had $2 n=84$ and the latter $2 n=72$. The cultivar Picasso's Paint Brush, which has linear leaves, was genetically mosaic with $2 n=$ $66,70,72$, and 82 .

Karyotypic variation. In addition to the variable chromosome numbers, each of the cultivars had a distinct karyotype (Table 1). Although the majority of chromosomes were metacentric and submetacentric regardless of cultivar, acrocentic chromosomes, i.e., $\mathrm{A}_{2}$ and $\mathrm{B}_{3}$, occurred in all the cultivars except 'Ice Tone' that had $\mathrm{A}_{2}$ only. Chromosomes of 'Ice Tone' were small, 1.5 to $2.1 \mu \mathrm{m}$, with the primary constrictions situated near the middle. 'Picasso's Paint Bush' had long chromosomes ranging from 3.3 to $5.1 \mu \mathrm{m}$ in length. Four cultivars, Gold Dust, Mother and Daughter, Ralph Davis Hybrid, and Piccasso's Paint Brush, had more than one secondary constriction. Because all seven cultivars in this study had distinct karyotypes, no relationships could be established between karyotype and leaf morphology as well.

\section{Discussion}

Variation in chromosome numbers. This study showed that the seven croton cultivars widely produced in Florida, similar to those cultivated in India and the Philippines, are
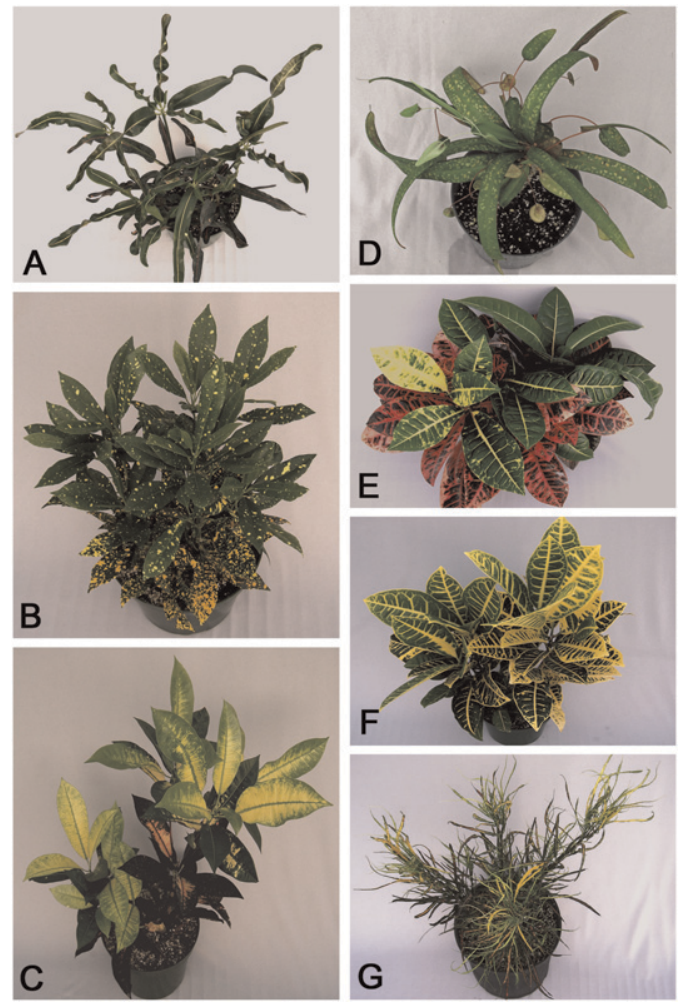

Fig. 1. The morphology of seven Codiaeum variegatum cultivars widely produced in Florida: (A) Curly Boy (narrow and spiral leaves); (B) Gold Dust (small, elliptic leaves spotted with bright yellow dots); (C) Ice Tone (small, elliptic leaves with yellowish variegation, which turns pinkish as leaves become mature); (D) Mother and Daughter (narrow leaves, a small leaf sprouting from the tip of a mature leaf joined by a slender stalk); (E) Ralph Davis Hybrid (broad leaves with yellow variegation, which turns to pinkish as leaves become mature); (F) Yellow Petra (broad leaves with broad and bright yellow veins); and (G) Piccasso's Paint Brush (linear leaves with multicolored center stripes).

Table 1. Chromosome number and karyotype of seven Codiaeum variegatum cultivars.

\begin{tabular}{lcl}
\hline Cultivar & Chromosome number & \multicolumn{1}{c}{ Karyotype } \\
\hline Curly Boy & $2 n=72$ & $52 \mathrm{~A}_{1}+12 \mathrm{~A}_{2}+2 \mathrm{~B}_{1}+2 \mathrm{~B}_{2}+4 \mathrm{~B}_{3}$ \\
Gold Dust & $2 n=80$ & $60 \mathrm{~A}_{1}+2 \mathrm{~A}_{2}+12 \mathrm{~B}_{1}+4 \mathrm{~B}_{3}+2 \mathrm{~B}_{4}$ \\
Ice Tone & $2 n=76$ & $70 \mathrm{~A}_{1}+4 \mathrm{~A}_{2}+2 \mathrm{~B}_{1}$ \\
Mother and Daughter & $2 n=96$ & $66 \mathrm{~A}_{1}+12 \mathrm{~A}_{2}+2 \mathrm{~B}_{1}+12 \mathrm{~B}_{2}+2 \mathrm{~B}_{3}+2 \mathrm{~B}_{4}$ \\
Ralph Davis Hybrid & $2 n=84$ & $55 \mathrm{~A}_{1}+6 \mathrm{~A}_{2}+7 \mathrm{~B}_{1}+1 \mathrm{~B}_{2}+5 \mathrm{~B}_{3}+10 \mathrm{~B}_{4}$ \\
Yellow Petra & $2 n=72$ & $54 \mathrm{~A}_{1}+12 \mathrm{~A}_{2}+4 \mathrm{~B}_{2}+2 \mathrm{~B}_{3}$ \\
Piccasso's Paint Brush & $2 n=66$ & $54 \mathrm{~A}_{1}+6 \mathrm{~A}_{2}+2 \mathrm{~B}_{1}+2 \mathrm{~B}_{2}+2 \mathrm{~B}_{4} ;$ \\
& $2 n=70$ & $50 \mathrm{~A}_{1}+6 \mathrm{~A}_{2}+6 \mathrm{~B}_{1}+4 \mathrm{~B}_{2}+4 \mathrm{~B}_{3} ;$ \\
& $2 n=72$ & $50 \mathrm{~A}_{1}+6 \mathrm{~A}_{2}+7 \mathrm{~B}_{1}+4 \mathrm{~B}_{2}+5 \mathrm{~B}_{3} ;$ \\
& $2 n=82$ & $60 \mathrm{~A}_{1}+8 \mathrm{~A}_{2}+2 \mathrm{~B}_{1}+6 \mathrm{~B}_{2}+2 \mathrm{~B}_{3}+4 \mathrm{~B}_{4 ;}$ \\
\hline
\end{tabular}

$\mathrm{A}=$ Chromosome without secondary constrictions.

$\mathrm{B}=$ Chromosome with one to three secondary constrictions.

$\mathrm{A}_{1}=$ Metacentric to submetacentric chromosome with a central primary constriction at middle or submiddle of the chromosome.

$\mathrm{A}_{2}=$ Acrocentric chromosome with a primary constriction close to the terminal area.

$\mathrm{B}_{1}=$ Centromere to submetacentric chromosome with a secondary constriction on the longer arms dividing the long arm into equal parts.

$\mathrm{B}_{2}=$ Centromere to submetacentric chromosome with a secondary constriction on the longer arms dividing the longer arm into a large and small part.

$\mathrm{B}_{3}=$ Acrocentric chromosome with a secondary constriction close to end of the longer arm, thus dividing the longer arm into large and small part.

$\mathrm{B}_{4}=$ The chromosome with more than one secondary constriction.

polyploid with $2 n=66$ to 96 . It is worth noting that the basic chromosome number of $C$. variegatum still remains uncertain. Sharma and Bal (1958) proposed $2 n=16$, Pancho and Hilario (1963) suggested $2 n=24$, and Ogunwenmo et al. (2007) reported a croton cultivar with $2 n=24$. Regardless of $2 n=$ 16 or $2 n=24$, the present study showed that five of the seven cultivars had different somatic chromosome numbers; only 'Curly
Boy' and 'Yellow Petra' had $2 n$ chromosome numbers of 72 (Table 1). Thus, the results from this study provide little further insight into the basic chromosome number question but suggest that some cultivars could be aneuploid. If $2 n$ chromosome numbers were 16 as proposed by Sharma and Bal (1958), the predicted numbers should include $2 n=64$, 80 , and 96 . The present study only has 'Gold Dust' with $2 n=80$ and 'Mother and Daughter' 
$2 n=96$. On the other hand, if $2 n$ chromosome numbers were 24 as suggested by Pancho and Hilario (1963), the predicted numbers should include 48, 72, and 96. In this study, only 'Curly Boy' and 'Yellow Petra' (both with $2 n=72)$ and 'Mother and Daughter' $(2 n=96)$ fit the prediction. If both $2 n=16$ and $2 n=24$ held true, the remaining three cultivars, Ice Tone $(2 n=76)$, Ralph Davis Hybrid $(2 n=$ 84), and Piccasso's Paint Brush $(2 n=66,70$, and 82), could be aneuploid.

Aneuploidy is often associated with polyploidization as a result of mitotic and meiotic difficulties (Comai, 2005). Chennaveeraiah and Wagley (1985) observed endoreduplication, irregular chromosome segregation, spindle multipolarity, and unusual nucleus shape in crotons and proposed that such irregularities contributed to the wide range of chromosome numbers in $C$. variegatum as documented in the studies conducted by Ogunwenmo et al. (2007), Pancho and Hilario (1963), and Sharma and Bal (1958) as well as the present study. Distinct phenotypes could occur in polyploid populations as a result of gene duplication (Henny et al., 2009; Levin, 1983; Soltis et al., 2009; Tsukaya, 2008).

This study also found genetic mosaics in 'Picasso's Paint Brush' $(2 n=66,70,72$, or 82). Chromosome numbers $2 n=108,116$, and 120 were also reported in root cells of $C$. variegatum 'Maharaja of Mysore' (Sharma and Bal, 1958). Furthermore, Chennaveeraiah and Wagley (1985) found that somatic chromosome numbers of 'Spotted Giant' in root tips were $2 n=108$, but in shoot tips $2 n=78$, $100,102,106,118,120$, and 134. Wide chromosomal variation within a cultivar often causes chromosomal instability. Selfing 'Spotted Giant' resulted in 27 progenies, of which 19 had different chromosome numbers varying from $2 n=70$ to 146 with different phenotypes (Chennaveeraiah and Wagley,
1985). The present study did not examine somatic chromosome numbers in shoot-tip cells. Whether genetic mosaics occurred in shoot-tip cells of any of the seven cultivars is unknown. It could be possible that some of the cultivars developed in Florida could also be derived from the progeny of selfed populations and that propagation by cuttings through decades of commercial production fixed the phenotypes.

Cultivar differences in karyotype. Each of the seven croton cultivars had its own karyotype (Table 1; Fig. 2). Particularly, all seven cultivars had acrocentic chromosomes, i.e., $A_{2}$ and $B_{3}$ (Table 1), which may suggest that inversions of chromosomal segments occurred. Differences in karyotypic morphology reflect differences in gene arrangement, which can drastically affect the way in which genes can become segregated and recombined (Stebbins, 1971), thus affecting plant morphology (Sharma and Sharma, 1959).

No relationship between leaf morphology and chromosome number. Considering the fact that the most distinct characteristic of crotons is their leaf shape and variegation patterns (Fig. 1), leaf morphology was the focus of this study. In general, individuals or cultivars of the same species have the same number of chromosomes; correspondingly, they are morphologically similar (Sharma and Sharma, 1959; Stebbins, 1950; Vavilov, 1922). Because of the differences in chromosome numbers and karyotypes as well as wide variation in leaf shapes and variegation patterns among the studied cultivars, no correlation was established between chromosome numbers or karyotype and leaf morphology. This conclusion concurs with the results from the study conducted by Ogunwenmo et al. (2007) using six crotons cultivated in Nigeria, of which four of six cultivars had $2 n=$ 60 ; the four had spiral, small, oak, and narrow
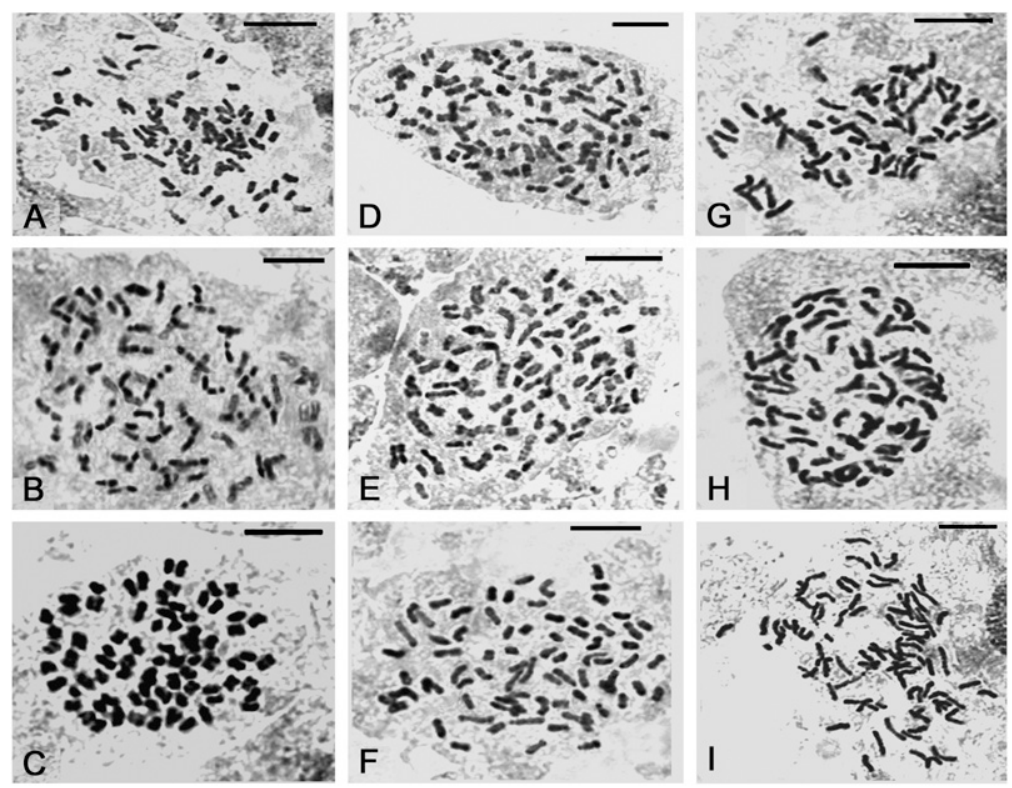

Fig. 2. Mitotic metaphase chromosomes in root-tip cells of seven Codiaeum variegatum cultivars: (A) Curly Boy $(2 n=72)$; (B) Gold Dust $(2 n=80)$; (C) Ice Tone $(2 n=76)$; (D) Mother and Daughter $(2 n=$ 96); (E) Ralph Davis Hybrid $(2 n=84)$; (F) Yellow Petra $(2 n=72)$; (G-I) Piccasso's Paint Brush $(2 n=$ $66,70,82$, respectively). Bar $=10 \mu \mathrm{m}$. leaf types, respectively. The one with $2 n=24$ had semioak leaves and the other, $2 n=30$, had narrow leaves.

Taken together, the seven popular crotons cultivated in Florida, similar to those cultivated in India and the Philippines, are polyploid. Polyploidization with different chromosome numbers, including aneuploids and genetic mosaics as well as variable karyotypes, could be the cytogenetic basis for the diverse morphological variation. Further study using molecular markers is warranted to determine if morphological, particularly leaf, variation is related to molecular marker polymorphisms.

\section{Literature Cited}

Brown, B.F. 1995. A Codiaeum encyclopedia: Crotons of the world. Valkaria Tropical Garden, Valkaria, FL.

Chen, J., D.B. McConnell, D.J. Norman, and R.J. Henny. 2005. The foliage plant industry. Hort. Rev. (Amer. Soc. Hort. Sci.) 31:47-112.

Chen, J. and R.H. Stamps. 2006. Cutting propagation of foliage plants, p. 203-228. In: Dole, J.M. and J.L. Gibson (eds.). Cutting propagation: A guide to propagating and producing floriculture crops. Ball Publishing, Batavia, IL.

Chennaveeraiah, M.S. and S.K. Wagley. 1985. Chromosome mosaicism in cultivars of garden crotons (Codiaeum variegatum). Nucleus 28: $8-13$.

Comai, L. 2005. The advantages and disadvantages of being polyploid. Nat. Rev. Genet. 6:836-846.

Dyer, A.F. 1979. Investigating chromosomes Edward Arnold, London, UK.

Henny, R.J., J. Holm, J. Chen, and M. Scheiber. 2009. In vitro induction of tetraploids in Dieffenbachia $\times$ 'Star Bright M-1' by colchicine. HortScience 44:646-650

Levin, D.A. 1983. Polyploidy and novelty in flowering plants. Amer. Nat. 122:1-25.

Ogunwenmo, K.O., O.A. Idowu, C. Innocent, E.B. Esan, and O.A. Oyelana. 2007. Cultivars of Codiaeum variegatum (L.) Blume (Euphorbiaceae) show variability in phytochemical and cytological characteristics. Afr. J. Biotechnol. 6:2400-2405.

Pancho, J.V. and F. Hilario. 1963. Chromosome numbers and intraspecific hybridization in croton (Codiaeum variegatum Blume). Philippine Agr. 47:104-112.

Sharma, A.K. and A.K. Bal. 1958. A cytological study on the different varieties of Codiaeum variegatum $\mathrm{BL}$. as means of finding out the mechanism of their evolution. Nucleus 1:223266.

Sharma, A.K. and A. Sharma. 1959. Chromosomal alterations in relation to speciation. Bot. Rev. 25:514-544.

Soltis, D.E., V.A. Albert, J. Leebens-Mack, C.D. Bell, A.H. Paterson, C. Zheng, D. Sankoff, C.W. DePamphilis, P.K. Wall, and P.S. Soltis. 2009. Polyploidy and angiosperm diversification. Amer. J. Bot. 96:336-348.

Stebbins, G.L. 1950. Variation and evolution in plants. Columbia Univ. Press, New York, NY.

Stebbins, G.L. 1971. Chromosomal evolution in higher plants. Addison-Wesley Pub. Co., Menlo Park, CA.

Tsukaya, H. 2008. Controlling size in multicellular organs: Focus on the leaf. PLoS Biol. 6:13731376.

The Croton Society. 2009. Croton major leaf types. 28 Dec. 2009. <http://www.crotons.org>

Vavilov, N.I. 1922. The law of homologous series in variation. J. Genet. 12:1. 